DOI: $10.2478 /$ achi-2020-0012

\title{
DECAY RESISTANCE OF BEECH WOOD AGAINST WHITE ROT FUNGUS
}

\author{
Amir Ghavidel $^{\mathrm{a}}$, Ion Sandu ${ }^{\mathrm{b}}$, Viorica Vasilache ${ }^{\mathrm{b} *}$ \\ ${ }^{a}$ Faculty of Geography and Geology, Geoscience Doctoral School \\ “Al.I. Cuza” University Iasi, 22 Carol I Bd, Iasi 700506, Romania \\ ${ }^{b}$ Institute of Interdisciplinary Research, Arheoinvest Centre "Al.I. Cuza” \\ University Iasi, 11 Carol I Bd, Iasi 700506, Romania
}

\begin{abstract}
Decay resistance of modified beech wood against the white rot fungus was investigated. Beech (Fagus orientalis), which is a nondurable wood was modified by propionic anhydride at different temperatures, concentrations and times without using any catalyst. Propionylation degree was determined by calculating volume change (VC) and weight percentage gain (WPG) after acetone extraction. WPGs varies according with applied treatment conditions. VC increased linearly with increasing WPG. The decay resistance of the propionylated wood against treatments versicolor was determined according to ASTM D1413 standard test methods. Weight loss (WL) decay with WPG increased was significantly noticed. WPG of about $17 \%$ was found to be the threshold level of the propionylated wood.
\end{abstract}

Keywords: Beech wood; Propionic anhydride; Weight percentage gain; White rot fungus

\section{Introduction}

Wood is a natural substance that is destroyed by biological agents such as fungi. Therefore, wood protection is important especially when exposed to the outside environment. Saturation of wood with aqueous or

\footnotetext{
*Viorica, Vasilache,e-mail: viorica_18v@yahoo.com
} 
organic dispersions in the form of insect-fungal solutions, emulsions or pastes is one of the most common methods of protecting wood against harmful biological agents used from the past to the present. But because of the environmental and human health concerns that are induced by excessive use of these materials, in developed countries, wood preservatives are being replaced with non-toxic preservatives. ${ }^{1-3}$ Non-toxic methods that have been studied for wood preservation include chemical modification of wood. Chemical modification of wood can be defined as the treatment of wood with chemicals that are able to functionalize hydroxyl groups. ${ }^{4,5}$ One of the most important methods of chemical modification is the method of sterilization. Currently, wood sterilization is used to kill insects and microorganisms. An important factor in this process is the required time to reach the optimal temperature to kill the insect and micro-organisms in the center of any wood configuration. Current heat sterilization regulations for these wood products require that a center temperature of $133^{\circ} \mathrm{F}$ that should be maintained for $30 \mathrm{~min}$. This additional time can differ widely depending on a variety of factors such as wood type, specific gravity, moisture content, cross-sectional measurements, initial temperature, heating temperature, medium heating (wet or dry heat), and method of stacking. Esterification is the reaction between the hydroxyl group of a wood component and the predominantly carboxylic group of carboxylic anhydride or carboxylic acid in the presence or absence of the catalyst, which results in an array of ester bonds between a small organic moiety and the wood matrix. Sterilization may improve some of the properties of wood. The anhydrides are divided into linear and cyclic groups. It is worth noting that the efficiency of linear anhydrides in improving the physical and biological properties of wood is more than cyclic anhydrides. ${ }^{6,7}$ Among wood esterification methods the 
anhydride treatment was a preferred approach. Many efforts were made to industrialize the acetylation process, and finally in 2007, this process was implemented and acetylated wood was marketed under the trade name Acquia $1 .^{8-11}$ The process cannot be applied to the soft essences, because the resulted organic acid after treatment may cause microfibril hydrolysis and implicitly their fragility.<smiles>[R]C(=O)OC([R])=[O+]O[14CH2][14CH2][14CH2][14CH2][14C]([R])=O</smiles>

Figure 1. Reaction of linear anhydrides with wood hydroxyl.

The main objective of this study was to determine the threshold of immunity of carrot propionylated Iranian beech against white rot carcass. Beech was used in this study because it has a suitable permeability and low natural durability. ${ }^{10-12}$

\section{Results and Discussion}

Propionylation of beech wood

Beech successfully reacted with propionic anhydride for 3-4 hours at 100-120 degree. Propionylation of beech wood was characterized by an increase in volume and weight (Figure 2 and Table 1). The increase in wood volume is due to the bulking effect of the reaction with propionic anhydride. As shown in Figure 2, the VC increases linearly with increasing WPG due to induced chemical modification. Some species may not react with propionic anhydride when no talisol or solvent is used. ${ }^{4,13}$ It should be noted, however, that the reaction temperature is essential for esterification. Thus, a temperature increase might be beneficial for wood 
propionylation. ${ }^{9,14}$ In this study, it was shown that propionylation of beech wood occurs using suitable reaction conditions.

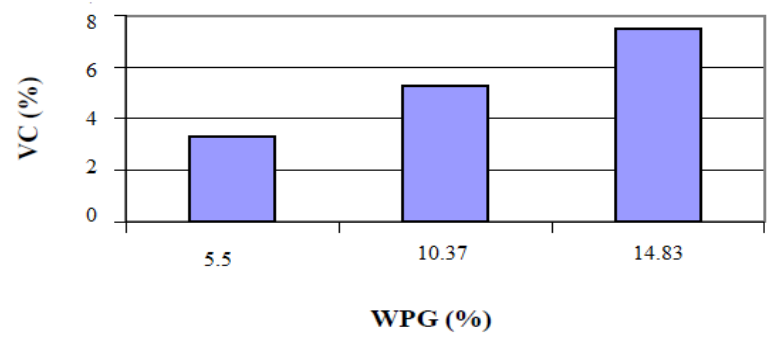

Figure 2. Average increase of modified beech wood volume and correlation with WPG.

Table 1. Characteristics of beech wood modified with propionic anhydride under different conditions.

\begin{tabular}{cccc}
\hline $\begin{array}{c}\text { Reagent used for } \\
\text { treatment }\end{array}$ & Treatment code & WPG (\%) & VC (\%) \\
\hline & A & 14.83 & 7.52 \\
Propionic & B & 10.37 & 5.3 \\
Anhydride & C & 5.5 & 3.3 \\
\hline
\end{tabular}

Resistance to decay of propionylated beech wood

Figure 3 shows the weight loss of propionylated specimens after the invasion of white rot carriers. There is a linear correlation between WPG and WL.

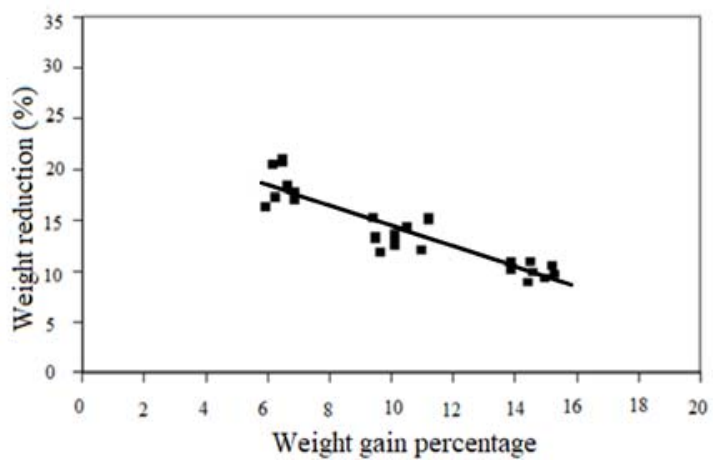

Figure 3. Weight loss of propionic anhydride modified samples against weight percentage gain. 
Data analysis by one-way analysis of variance at the confidence level of $95 \%$ showed that the final mean weight loss of the propionylated samples was significant (Table 2). Also, the difference of different treatments (propionylation with different WPG) was investigated by Tukey test at 5\% error level (Table 3). As can be seen in Table 3, all differences were significant and decreased with increasing WL and WPG.

Table 2. Analysis of variance of weight loss values of propionylated samples due to white rot.

\begin{tabular}{cccccc}
\hline & $\begin{array}{c}\text { Degrees } \\
\text { of } \\
\text { freedom }\end{array}$ & $\begin{array}{c}\text { sum of } \\
\text { squares }\end{array}$ & $\begin{array}{c}\text { The } \\
\text { mean of } \\
\text { squares }\end{array}$ & $\begin{array}{c}\text { Number } \\
\mathrm{F}\end{array}$ & $\begin{array}{c}\text { meaningful } \\
\text { level }\end{array}$ \\
\cline { 2 - 6 } Propionylation & 3 & 770.45 & 256.82 & 666.70 & 0.000 \\
Error & 32 & 12.33 & 0.39 & & \\
Total & 35 & 782.78 & & & \\
\hline
\end{tabular}

Table 3. Results of Tukey test on decreasing swelling of wood modified with propionic anhydride in different WPGs.

\begin{tabular}{ccccc}
\hline Percentage (\%) & 0 & 5.5 & 10.37 & 14.83 \\
\hline 0 & & $\mathrm{~S}$ & $\mathrm{~S}$ & $\mathrm{~S}$ \\
5.5 & $\mathrm{~S}$ & & $\mathrm{~S}$ & $\mathrm{~S}$ \\
9.59 & $\mathrm{~S}$ & $\mathrm{~S}$ & & \\
14.83 & $\mathrm{~S}$ & $\mathrm{~S}$ & $\mathrm{~S}$ & \\
\hline
\end{tabular}

where $\mathrm{S}=$ Significant

According to the data shown in Figure 3, the caries immunity threshold was calculated to be about $17 \%$. The caries immunity thresholds obtained in this study are within the range of caries immunity reported for European and Japanese acetylated beech. ${ }^{10,15}$

\section{Experimental}

Completely radial tangential samples of beech (Fagus orientalis) wood were prepared in dimensions of $20 \times 20 \times 5 \mathrm{~mm}$. Then wood samples were treated with acetone for 8 hours. All extracted samples were counted 
with acetone and dried in oven at $103{ }^{\circ} \mathrm{C}$ for 24 hours. After drying in oven, the weight of all samples was measured by a weighing scale with $0.0001 \mathrm{~g}$ accuracy. The samples were then saturated with propionic anhydride (anhydrous or solubilized in acetone to a molar concentration) under vacuum. Then, the samples were treated with propionic anhydride (pure or at a concentration of $1 \mathrm{M}$ ) at different times and temperatures (Table 4).

Table 4. Conditions for the reaction of esterification of the beech wood with propionic anhydride.

\begin{tabular}{cccccc}
\hline Chemical & $\begin{array}{c}\text { Treatment } \\
\text { code }\end{array}$ & Compactness & Solvent & $\begin{array}{c}\text { Heating } \\
\text { time }\end{array}$ & $\begin{array}{c}\text { Temperature } \\
{ }^{\circ} \mathrm{C}\end{array}$ \\
\hline Propionic & $\mathrm{A}$ & Pure & - & 4 & 120 \\
Anhydride & $\mathrm{B}$ & Pure & - & 3 & 100 \\
& $\mathrm{C}$ & $1 \mathrm{M}$ & $\begin{array}{c}\text { Acetone } \\
\left(\mathrm{CH}_{3} \mathrm{COCH}_{3}\right)\end{array}$ & 1 & 100 \\
\hline
\end{tabular}

Five replicates were considered. After completion of reaction time, all samples were treated with acetone for $8 \mathrm{~h}$ to remove residual propionic anhydride and released propionic acid from the reaction. The The treated samples were dried in $103{ }^{\circ} \mathrm{C}$ oven for 24 hours and the volume of laboratory weight was re-measured in order to evaluate VC and WPG attributed to each treated sample. ${ }^{11,12,16}$

\section{Conclusions}

Beech wood can be propionylated using a classical uncatalyzed reaction. Propionylation significantly improves resistance to carrion rot, so that in WPG about $17 \%$ of this wood is fully protected against white fungus. The increase in wood volume is due to the bulking effect of the reaction with propionic anhydride. Some species may not react with propionic anhydride when no talisol or solvent is used. This study clearly illustrates that beech wood propionylation can be achieved. 


\section{References}

1. Sandu, I.C.A.; Hayashi, M.; Vasilache, V.; Cozma, D. G.; Pruteanu, S.; Urma, M.; Sandu, I. Influence of organic solvents and dispersions on wooden supports of paintings. Rev. Chem. (Bucharest) 2015, 66(4), 587-595.

2. Hayashi, M.; Sandu, I.; Ciocan, A. C.; Vasilache, V.; Sandu, I. C. A. The impact of some active compounds implied in the preservation of the old wood. Acta Universitatis Cibiniensis Seria F, Chemia 2008, 11(2), 27-39.

3. Sandu, I.; Vasilache, V.; Sandu, I. C. A.; Hayashi, M. New Method of Determining the Normal Range of Hydric-Equilibrium Variation in Wood with Multiple Applications. Rev. Chim. (Bucharest) 2010, 61(12), 1212-1218.

4. Jones, D. The potential for modified materials in the panel products industry - a thematic network approach. In Proceeding of the fifth European Panel Products Symposium, Llandudno, Wales, U.K., 2001, pp 184-197.

5. Bekers, E. P. J.; Milits, H.; Stevens, M. Resistance of acetylated wood to basidiomycetes, soft rot and blue stain. International Research Group on Wood Preservation. doc. IRG/WP/94-40021, 1994, 11p, http://hdl.handle.net /1854/LU-247587.

6. Hill, C. A. S. Wood modification: chemical, thermal and other processes, Wiley, London, 2006.

7. Hill, C. A. S.; Papadopoulos, A. N.; Payane, D. Chemical modification employed as a mean of probing the cell wall micropore of pine sapwood. Wood Sci. Technol. 2004, 37(6), 475-488.

8. Hill, C. A. S.; Hale, M. D.; Farahani, M. R. M.; Foster, S.; Sutties, E. D.; Jones, D.; Papadopoulos, A. N. Decay resistance of anhydride modified wood. In (Hill CAS) Proc. 1st Eur. Conf. on Wood Modification, Ghent University, Ghent, Belgium, 2003, pp. 143-152.

9. Li, J. Z.; Furuno, T.; Katoh, S.; Uehara, T. Chemical modification of wood by anhydrides without solvents or catalysts. J. Wood Sci. 2000, 46(3), 215-221.

10. Milits, H.; Son, D. W.; Gomez-Hemadez, L.; Sierra- Alvarez, R. The effect of fungal degradation on the chemical composition of acetylated 
beech wood. International Research Group on Wood Preservation. Document no. IRG/WP 40267, 2003.

11. Takahashi, M.; Imamura, Y.; Tanahashi, M. Effect of acetylation on decay resistance of wood against brown rot, white rot and soft rot fungi. International Research Group on Wood Preservation. Document no. IRG/WP 3540, 1989.

12. Omidvar, A.; Abdolmaleki, J. Making Wood Polymer Composite Using Direct Heat Technique. J. Agric. Sci. Nat. Resour. 2003, 9(4), 215-221.

13. Omidvare, A.; Amoozadeh Omrani, M. Investigation on treatability of paulownia wood using polymerization technique. J. Agric. Sci. Nat. Resour. 2005, 12(5), 128-135.

14. Lande, S.; Westin, M.; Schneider, M. Properties of furfurylated wood. J. For. Res. 2004, 19(5), 22-30.

15. Omidvare, A. Wood polymer composites, 1th Ed., Gorgan University of Agricultural Sciences and Natural Resources press, Gorgan, Iran, 2009.

16. Baysal, E.; Yalinkilik, M. K.; Altinok, M.; Sonmez, A.; Peker. H.; Colak, M. Some physical, biological, mechanical, and fire properties of wood polymer composite (WPC) pretreated with boric acid and borax mixture. Constr. Build. Mater. 2007, 21, 1879-1885. 